\title{
Association between Hyperglycemia, C-Reactive Protein and Other Risk Factors in Patients at Cardiovascular Risk
}

\author{
Sandra Maria Barbalho ${ }^{1,2 *}$, Ricardo José Toffano ${ }^{3}$, Marcelo Dib Bechara1, \\ Karina Rodrigues Quesada1, Marie Oshiiwa², Claudemir Gregório Mendes', \\ Marcia Rocha Gabaldi ${ }^{1}$ \\ ${ }^{1}$ Department of Biochemistry and Celular Biology, Medical School of Marília, UNIMAR, Marília, Brazil \\ ${ }^{2}$ Food and Technology School of Marília (FATEC), São Paulo, Brazil \\ ${ }^{3}$ Department of the Cardiac Surgery Unit and Hemodynamics, Medical School UNIMAR (Hospital \\ Beneficente UNIMAR), Marília, Brazil \\ Email: "smbarbalho@gmail.com
}

Received 23 November 2015; accepted 29 January 2016; published 4 February 2016

Copyright (C) 2016 by authors and Scientific Research Publishing Inc.

This work is licensed under the Creative Commons Attribution International License (CC BY).

http://creativecommons.org/licenses/by/4.0/

(c) (i) Open Access

\section{Abstract}

Type 2 diabetes (DM2) is a syndrome characterized by postprandial hyperglycemia normally due to peripheral resistance to insulin and accounts for approximately $90 \%$ of diabetes cases worldwide and it is usually related to dyslipidemia, overweight/obesity and physical inactivity and increase in the risk of cardiovascular disease. This study aimed to compare the metabolic and inflammatory profile of hyperglycemic with non-hyperglycemic subjects in a group of patients undergoing coronary arteriography. Our group of patients showed that $63.16 \%$ presented glycaemia above $99 \mathrm{mg} / \mathrm{dL}$ (from the hyperglycemic patients, 31 individuals were classified as glucose intolerant and 29 as diabetic). Significant differences were found for glycaemia, LDL-c (Low Density Lipoprotein), and hs-CRP (high sensitivity $C$ reactive protein) levels. Nevertheless it is possible to observe that patients with higher glycaemia showed increased values of Total Cholesterol, Triglycerides, LDL-c, Castelli Index I and II and estimative of LDL-c size particle and decreased HDL-c (High Density Lipoprotein) values. The comparison between hs-CRP levels and biochemical parameters shows significant differences for Body Mass Index, Triglycerides, HDL-c and the estimative of LDL-c particle. Also, the presence of Metabolic Syndrome is more prevalent in patients with high levels of hs-CRP. Diabetes patients have more significant increase in morbidity and mortality than the general population frequently due to further complications associated with the resistance to insulin. It is indispensable to outline the anthropometric and biochemical profile from hyperglycemic patients in order to work on secondary prevention of cardiovascular disease.

\footnotetext{
"Corresponding author.
} 


\section{Keywords}

\section{Hyperglycemia, C-Reactive Protein, Angiography, Castelli Index, Lipids}

\section{Introduction}

Glucose intolerance may lead to type 2 diabetes (DM2) over a variable period of time, resulting in oxidative damages and endoplasmatic reticulum stress unleashed by the insulin resistance. Associated with that, it is commonly seen the increase of circulating pro-inflammatory cytokine levels and low-intensity islet inflammation suggesting that the inflammation process may contribute to beta cell dysfunction and death in these patients [1]-[5].

DM2 is a syndrome characterized by postprandial hyperglycemia normally due to peripheral resistance to insulin and accounts for approximately $90 \%$ of diabetes cases worldwide and it is usually related to overweight/ obesity and physical inactivity. The number of DM2 patients is increasing enormously, reaching epidemic proportions and becoming a serious public health problem [5] [6].

It is well established that DM2 patients are at increased risk of developing cardiovascular diseases (CVD) and are more likely to die of these diseases than non-diabetics subjects. Also associated is the Metabolic Syndrome (MS) that includes a number of risk factors that play important role in high morbidity. The obesity, mainly the visceral adipose tissue, is related to the CVD due to the release of inflammatory mediators such as tumor necrosis factor $\alpha$ (TNF- $\alpha$ ), interleukin-1 (IL-1), IL-6, resist in and inhibitor of plasminogen activator-1 (PAI-1) leading to a low intensity inflammatory process and resulting in a local immune response and production of pro-inflammatory markers as C reactive protein (CRP) [7]-[11].

CRP is produced by the liver and adipocytes and its levels may increase in response to active infection or acute inflammation. It is regulated by cytokines IL-1, IL-6 and TNF- $\alpha$ and moderate increases are linked to chronic inflammatory conditions such as atherosclerosis independently of the lipid parameters. It is also related to insulin resistance and hyperglycemia [6] [12]-[14].

Considering that the glucose intolerance and DM2 are related to the MS, increase in CRP levels and CVD, this study aims to compare the metabolic and inflammatory profile of hyperglycemic with non-hyperglycemic subjects in a group of patients undergoing coronary arteriography.

\section{Materials and Methods}

The experimental protocols used in this study were approved by the Ethics Committee of the University of Marilia (Protocol 449/Record 25000.113733/2010-14) and started after the subjects signed a Free and Informed Consent Form (Resolution 196/10 of October 1996-National Health Council—CNS). The procedures of the experimental protocol followed the Ethical Standards of the Institutional Ethics Committee and the Helsinki Declaration of 1975, which was revised in 2008.

This work was conducted during the second half of 2013at the Hemodynamic Laboratory of the University Hospital in the city of Marilia-state of São Paulo, Brazil. We have studied 95 subjects (54 men and 43 women 36 to 88 years old) undergoing coronary arteriography. This group of patients was chosen in order to study the metabolic and inflammatory profile of normal and hyperglycemic individuals under this kind of procedure. Height and weight were also evaluated to calculate the body mass index (BMI). Waist circumference (WC) was also measured.

Venous blood was collected by BD vacutainer system to verify glycaemia (subjects with glycaemia $\geq 100$ $\mathrm{mg} / \mathrm{dL}$ and $\leq 126 \mathrm{mg} / \mathrm{dL}$ were considered glucose intolerant (GI); glycaemia $>126 \mathrm{mg} / \mathrm{dL}$ were considered DM), lipid profile (total cholesterol (TC), Low Density Lipoprotein cholesterol (LDL-C) and High Density Lipoprotein Cholesterol (HDL-c) and triglycerides (TG)) and levels of high sensitivity-CRP (hs-CRP). Biochemical parameters followed São Francisco Laboratory protocol at the University Hospital of the University of Marilia, SP, Brazil. The results of biochemical and anthropometric profile followed Lloyd-Jones et al. [15]. Castelli Index I and II were calculated, using TC/HDL-c and LDL-c/HDL-c ratios and to calculate the estimative of Low Density Lipoprotein particle size it was used the ratio TG/HDL-c. Values lower than $2.0 \mathrm{mg} / \mathrm{dL}$ considerate that the particles are small and dense (small dense LDL-c: sdLDL-c). 
The presence of alterations in at least three of the following parameters were evaluated to classify patients as possessing or not Metabolic Syndrome (MS): BMI, glycaemia, TG, HDL-c and blood pressure (data of blood pressure was used in order to help in the classification of MS, but they were not included in the tables or figures presented in the results section).

The data were analyzed using the statistical program R version 2.15.2. Quantitative variables were presented descriptively as mean, median, minimum and maximum values and standard deviation, and qualitative variables were analyzed by calculating the absolute and relative frequencies. Inferential analyses were used in Pearson's chi-square test and Fisher's exact test or its extension for comparison of the categorical variables. Analysis of variance (ANOVA) with a fixed factor and its non-parametric correspondent were used in the comparison of the patients' age (years). Spearman's correlation analysis was applied to assess the correlation between levels of CRP (mg/dL) and body mass index $\left(\mathrm{kg} / \mathrm{m}^{2}\right)$, waist circumference $(\mathrm{cm})$, total cholesterol (mg/dL), HDL-c (mg/dL), LDL-c (mg/dL), triglycerides (mg/dL), blood glucose (mg/dL), CI-I, CI-II and the estimative of LDL-c particle (sdLDL-c). For the Correlation Test we have included only the figures with statistical significance.

A level of significance $\alpha$ of 5\% was applied to all the conclusions obtained from the inferential analysis.

\section{Results}

Our group of studied patients undergoing arteriography show that $63.16 \%$ presented glycaemia above $99 \mathrm{mg} / \mathrm{dL}$ (from the hyperglycemic patients, 31 individuals were classified as glucose intolerant and 29 as diabetic). Table 1 shows that, from the 95 patients undergoing angiography, 95.0\% of the DM patients were classified as possessing MS. Fisher's exact test showed significant differences between hyperglycemic and non-hyperglycemic groups when comparing to the presence of MS (p-valor $=0.0121$ ).

Table 2 exhibits the comparison between hyperglycemic and non-hyperglycemic groups and shows non-significant differences in age, BMI and WC, but hyperglycemic patients tend to exhibit higher values of BMI and WC when compared to the normal patients.

In Table 3 it is possible to compare the biochemical parameters of the subjects, according to the presence of hyperglycemia. Significant differences were seen only for glucose, LDL-c, and hs-CRP levels. Nevertheless it is possible to observe that patients with higher glycaemia show increased values of TC, TG, LDL-c, glucose, Castelli Index I and II and estimative of LDL-c size particle and decreased HDL-c values.

The comparison between hs-CRP levels and biochemical parameters is shown in Table 4. Significant differences were observed for BMI, TG, HDL-c and the estimative of LDL-c particle (TG/HDL-c). However, individuals with high and moderate levels of hs-CRP tend to have higher values of CT, LDL-c, WC, Castelli Index I and II.

Figure 1 show the Correlation Test with significant differences in the hyperglycemic groups (not significant results were not presented here).

Figure 2 shows that most patients classified as having high and moderate levels of hs-CRP present higher percentage of MS.

\section{Discussion}

Our results show that most subjects undergoing arteriography are hyperglycemic or are classified as DM and almost all of these possess MS (Table 1). Postprandial hyperglycemia is known as a feature of the early stage of DM2 and impaired glucose tolerance caused by overt interference in the insulin action. The insulin resistance and modifications in the reference ranges of HDL-c and TG, WC and obesity are closely correlated and may characterize the MS which is a serious public health problem in both sexes worldwide. MS has a polygenicorigin and it is represented by a number of risk factors for developing DM2 and CVD. These risk factors are commonly represented by obesity (that often leads to MS, represented by a cluster of inter-related risk factors for developing DM and atherosclerosis), glucose intolerance, decreased HDL-c, increased TG, WC and hs-CRP and high blood pressure. Obesity, mainly related to the increase in the volume of the visceral adipose tissue, plays a fundamental role in the morbidity and mortality of the patients. Obesity in association with MS leads to the production, besides CRP, of high levels of proinflammatory markers [12]-[14]. Moderate increase in the levels of hs-CRP is associated with chronic inflammatory conditions such as atherosclerosis [6] [12] [14] [16].

No significant differences in the anthropometric profile of hyperglycemic and non-hyperglycemic subjects were observed (Table 2) and only LDL-c, hs-CRP and glycaemia showed significant differences in the groups 
Table 1. Subjects of the study according to the presence or not of hyperglycemia and Metabolic Syndrome (MS).

\begin{tabular}{cccc}
\hline Parameter & $\begin{array}{c}\text { Hyperglycemic } \\
(\mathrm{n}=60 / 63.16 \%)\end{array}$ & $\begin{array}{c}\text { Non-hyperglycemic } \\
(\mathrm{n}=35 / 36.84 \%)\end{array}$ & Total \\
\hline MS & $57(95.0 \%)$ & $27(77.1 \%)$ & $84(84.42 \%)$ \\
No MS & $3(5.0 \%)$ & $8(22.9 \%)$ & $11(11.58 \%)$ \\
\hline
\end{tabular}

DM2: Type2 diabetes mellitus; MS: Metabolicsyndrome.

Table 2. Characteristics of gender, age and anthropometric parameters of the studied subjects.

\begin{tabular}{ccc}
\hline Parameter & $\begin{array}{c}\text { Hyperglycemic } \\
(\mathrm{n}=60 / 63.16 \%)\end{array}$ & $\begin{array}{c}\text { Non-hyperglycemic } \\
(\mathrm{n}=35 / 36.84 \%)\end{array}$ \\
\hline Female/male & $(28 / 32)$ & $61.7 \pm 12.8(\mathrm{~A})$ \\
Age (years) & $65.5 \pm 10.3(\mathrm{~A})^{(1)}$ & $77.94 \pm 14.77(\mathrm{~A})$ \\
Weight $(\mathrm{kg})$ & $77.13 \pm 15.63(\mathrm{~A})$ & $1.67 \pm 0.09(\mathrm{~A})$ \\
Height $(\mathrm{m})$ & $1.65 \pm 0.09(\mathrm{~A})$ & $25.95 \pm 4.28(\mathrm{~A})$ \\
BMI $\left(\mathrm{kg} / \mathrm{m}^{2}\right)$ & $28.09 \pm 4.39(\mathrm{~A})$ & $94.20 \pm 12.30(\mathrm{~A})$ \\
\hline WC $(\mathrm{cm})$ & $97.60 \pm 13.3(\mathrm{~A})$ & \\
\hline
\end{tabular}

(1) Different letters indicate a significant difference between the treatments at a level of 5\%. BMI: body mass index; WC: waist circumference.

Table 3. Biochemical parameters of the subjects according to the glycaemia.

\begin{tabular}{ccc}
\hline Parameter & $\begin{array}{c}\text { Hyperglycemic } \\
(\mathrm{n}=60 / 63.16 \%)\end{array}$ & $\begin{array}{c}\text { Non-hyperglycemic } \\
(\mathrm{n}=35 / 36.84 \%)\end{array}$ \\
\hline TC $(\mathrm{mg} / \mathrm{dL})$ & $183.20 \pm 39.99(\mathrm{~A})^{(1)}$ & $178.07 \pm 45.43(\mathrm{~A})$ \\
HDL-c $(\mathrm{mg} / \mathrm{dL})$ & $44.28 \pm 12.11(\mathrm{~A})$ & $48.23 \pm 10.95(\mathrm{~A})$ \\
LDL-c $(\mathrm{mg} / \mathrm{dL})$ & $108.88 \pm 25.44(\mathrm{~A})$ & $101.78 \pm 35.24(\mathrm{~B})$ \\
CT/HDL-c & $4.24 \pm 1.57$ (A) & $4.16 \pm 1.38(\mathrm{~A})$ \\
TG/HDL-c & $1.82 \pm 4.39(\mathrm{~A})$ & $3.01 \pm 1.89$ (A) \\
LDL-c/HDL-c & $2.48 \pm 1.47$ (A) & $2.56 \pm 1.13$ (A) \\
hs-PCR (mg/dL) & $0.530 \pm 0.518$ (A) & $0.349 \pm 0.366$ (B) \\
Glucose (mg/dL) & $137.17 \pm 43.19$ (B) & $88.06 \pm 9.55$ (A) \\
TG (mg/dL) & $149.52 \pm 127.46$ (A) & $125.97 \pm 59.93$ (A)
\end{tabular}

(1) Different letters indicate a significant difference between the treatments at a level of 5\%. TC: total cholesterol; TG: triglycerides; HDL-c: high density lipoprotein; LDL-c: low density lipoprotein; TG: triglycerides; TC/HDL-c: Castelli Index I; LDL-c/HDL-c: Castelli Index II; TG/HDL-c: estimative of LDL-c particle; hs-CRP: high sensitivity C reactive Protein.

(Table 3), however, hyperglycemic individuals presented the higher values of TC, TG, Castelli Index I and II and alterations on the estimative of LDL-c particle. In this group, HDL-c levels were lower than those of individuals with glycaemia under $100 \mathrm{mg} / \mathrm{dL}$. Both groups presented BMI above normal values supporting the connection between obesity, DM and CVD as showed by other authors [17] [18]. Alterations in the lipid profile of DM patients are common in the literature, although with inconsistent findings when comparing the different fractions and components. High levels of TG, TC and LDL-c and low levels of HDL-c are normally associated with DM when they are compared to non-diabetic subjects. The absence of differences in the lipid profile in our study corroborates results obtained by Dongway et al. [6]. They studied a DM group and found higher TG and hs-CRP values but no differences in the LDL-c and HDL-c levels. They also found high prevalence of obesity in the DM group.

Our results also show increased values for biochemical and anthropometric profile as well as the presence of MS in individuals classified as having high hs-CRP values (Table 4) but significance were only found for HDL-c, TG and TG/HDL-c (estimative of LDL-c particle). As pointed before, the glucose intolerance that is commonly 


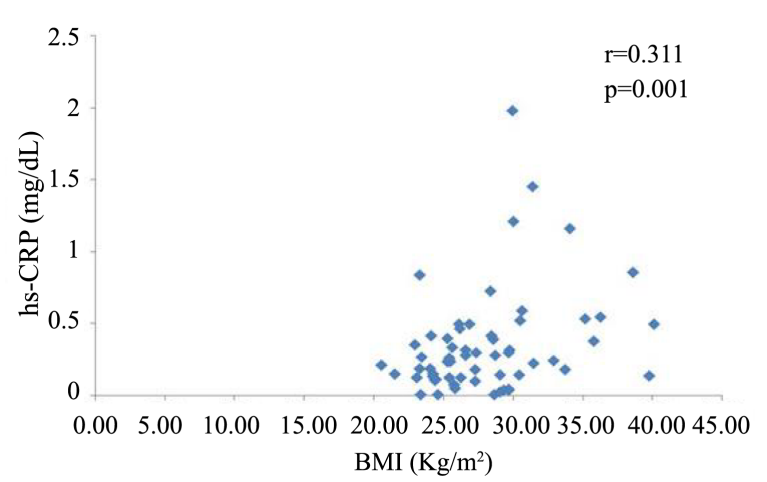

(a)

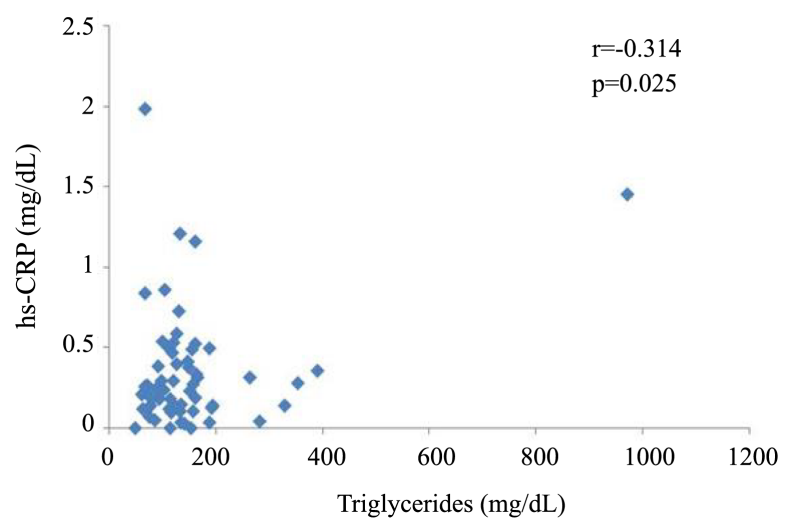

(c)

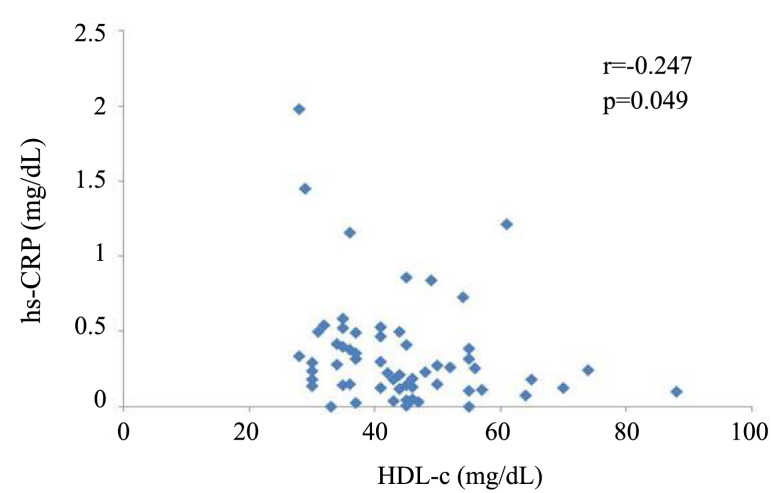

(b)

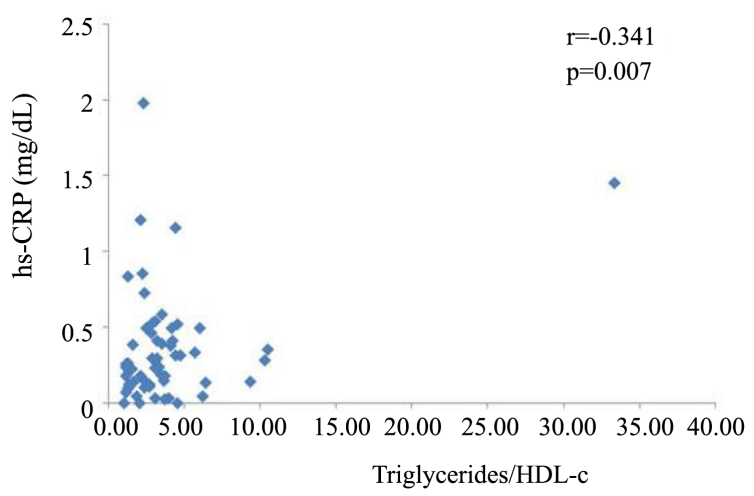

(d)

Figure 1. (a) Correlation between hs-CRP and BMI in hyperglycemic patients; (b) Correlation between hs-CRP and HDL-c in hyperglycemic patients; (c) Correlation between hs-CRP and HDL-c in triglycerides patients; (d) Correlation between hs-CRP and TG/HDL-c in hyperglycemic patients.

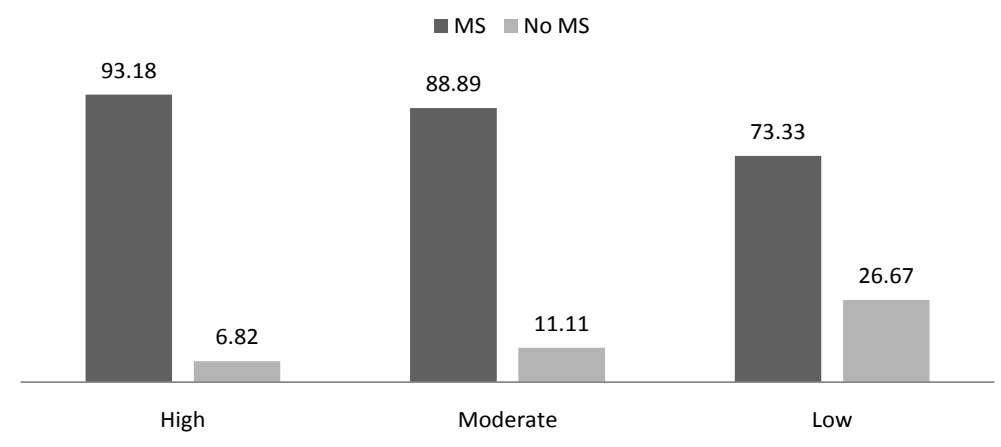

Figure 2. Presence of Metabolic Syndrome in the patients according to the hs-CRP levels $(p$-value $=0.115)$.

associated with obesity is also associated to the production of inflammatory biomarkers. The adipose tissue is known as an endocrine organ related to the maintenance of metabolic homeostasis. Nevertheless it has an important role in the development of obesity-related comorbidities including Diabetes. In addition, many studies show that hs-CRP independently, predicts vascular events and is related with MS and endothelial dysfunction [6] [19]-[22]. Authors have shown that hyperglycemia and obesity, besides the relationship with inflammatory processes, are also involved in the induction of oxidative stress. Hyperglycemia relates to inflammation and oxidative stress due to the formation of advanced glycation products, which in turn, relate to the synthesis of IL6 and activation of macrophages. These products are formed when there is glycation of proteins, lipids and nucleic acids, which can assist with the installation of oxidative stress and subsequent development of inflammatory and 
Table 4. Anthropometric and biochemical parameters in the subjects according to the hs-CRP.

\begin{tabular}{|c|c|c|c|c|}
\hline \multirow[b]{3}{*}{ Parameter } & \multirow{2}{*}{\multicolumn{2}{|c|}{$\begin{array}{l}\text { Hyperglycemic } \\
(\mathrm{n}=60 / 63.16 \%) \\
\text { hs-CRP }(\mathrm{mg} / \mathrm{dL})\end{array}$}} & \multirow{2}{*}{\multicolumn{2}{|c|}{$\begin{array}{c}\text { Non-hyperglicemic } \\
\text { (n = 35/36.84\%) } \\
\text { hs-CRP (mg/dL) }\end{array}$}} \\
\hline & & & & \\
\hline & $\mathrm{r}$ & pvalue & $\mathrm{r}$ & pvalue \\
\hline $\operatorname{BMI}\left(\mathrm{kg} / \mathrm{m}^{2}\right)$ & 0.311 & $0.015(\mathrm{~A})^{(1)}$ & 0.258 & $0.134(\mathrm{~B})$ \\
\hline $\mathrm{WC}(\mathrm{cm})$ & 0.132 & $0.314(\mathrm{~A})$ & 0.213 & $0.228(\mathrm{~A})$ \\
\hline $\mathrm{CT}(\mathrm{mg} / \mathrm{dL})$ & 0.219 & $0.092(\mathrm{~A})$ & 0.117 & $0.502(\mathrm{~A})$ \\
\hline HDL-c (mg/dL) & -0.247 & 0.049 (A) & 0.008 & 0.962 (B) \\
\hline LDL-c (mg/dL) & 0.168 & 0.202 (A) & 0.124 & $0.475(\mathrm{~A})$ \\
\hline TG (mg/dL) & 0.314 & $0.025(\mathrm{~A})$ & 0.018 & 0.915 (B) \\
\hline CT/HDL-c & 0.026 & $0.842(\mathrm{~A})$ & 0.185 & $0.286(\mathrm{~A})$ \\
\hline TG/HDL-c & 0.341 & 0.007 (A) & 0.055 & 0.749 (B) \\
\hline LDL-c/HDL-c & 0.181 & 0.166 (A) & 0.217 & $0.210(\mathrm{~A})$ \\
\hline
\end{tabular}

(1) Different letters indicate a significant difference between the treatments at a level of 5\%. TC: total cholesterol; TG: triglycerides; HDL-c: high density lipoprotein; LDL-c: low density lipoprotein; TG: triglycerides; TC/HDL-c: Castelli Index I; LDL-c/HDL-c: Castelli Index II; TG/HDL-c: estimative of LDL-c particle; hs-CRP: high sensitivity $\mathrm{C}$ reactive Protein.

thrombotic processes. This may help to explain the close relationship of DM2 with CVD [23]. Besides, there are several complex redundant biochemical pathways that may correlate or potentiate insulin resistance and chronic inflammation, which are related to diabetes and CVD [24]-[28].

Biomarkers have been analyzed as potential CVD risk factors and can be considered in the clinical stratification of these diseases. Authors have used CT/HDL-c, TG/HDL-c and LDL-c/HDL-c ratios as an additional tool to assist in the assessment of cardiovascular risk. TG/HDL-c is an estimative of low density lipoprotein particle and when this ratio is lower than $2 \mathrm{mg} / \mathrm{dL}$, sdLDL-c indicates higher CVC risk, because they are weakly recognized by LDL-c receptors and because they have greater susceptibility to peroxidation. The ratios CT/HDL-c and LDL/HDL-c have normal values when respectively less than 4.4 and 2.9 [29]-[31]. HDL-c and TG levels and sdLDL-c are independent risk factors for CVD [28]. Some authors show that increased levels of triglyceride represent a predictor of sdLDL-c and the quality of the LDL-c is more important than only LDL-c levels [32]-[35]. In our patients, no significant differences were observed in the hyperglycemic and non-hyperglycemic groups for these three ratios but the individuals presenting elevated glucose levels tend to exhibit higher values (Table 3). Similar comparison can be made with hs-CRP levels as observed in Table 4 where it is possible to observe significant differences in HDL-c levels as well as in TG and the estimative of LDL-c particles. Figure 1 shows the correlation analysis with significant differences in the hyperglycemic groups. Alterations in the lipid levels are considered as a key characteristic for DM individuals contributing significantly for the increase in the risk of CVD. The abnormalities in the lipid metabolism may be related to the reduced action of insulin at the tissues due to the peripheral resistance to this hormone [6] [36] [37].

Insulin mediates the uptake of free fatty acids muscle and adipose tissue. In the other hand, increased insulin resistance leads to the increase of free fatty acids delivered to the liver. This induces to the overproduction of very low density lipoprotein, with the clinical manifestation of hypertriglyceridemia and increase in the exchange of triglycerides to cholesterol ester from HDL-c and LDL-c, resulting in a higher catabolic rate of HDL-c and conversion of LDL-c to sdLDL-c that is more vulnerable to suffer oxidation and is able to penetrate the arterial wall contributing to the formation of atherosclerotic plaques [38] [39].

As all subjects of this study underwent arteriography, probably all of them have similar risks of CVD development, but general data show that these risk factors tend to appear as higher values in hyperglycemic patients. The number of patients may represent a limitation for our study. Besides, the evaluation of other inflammatory 
mediators as TNF- $\alpha$, interleukin-1 and interleukin- 6 could assist in other correlations analysis.

Diabetes patients have significant increase in morbidity and mortality than the general population frequently due to further complications associated with the resistance to insulin. It is indispensable to outline the anthropometric and biochemical profile from hyperglycemic patients because of the risk of heart disease in order to work on secondary prevention. Our results show that in our group of patients undergoing arteriography, the hyperglycemic subjects presented higher lipid and hs-CRP levels as well as higher chances to possess MS than the subjects with normal glycaemia. Management and the improvement of these risk factors and changes in lifestyle may provide better quality and consequently better life expectancy.

\section{Authors Contributions}

SMB and MDB: contributed in the conception and design of the manuscript. MO and MRG: performed the data analysis. RJT, CGM and KQ: helped on the discussion and on drafting of the article. SMB and RJT: wrote the paper.

\section{Conflict of Interests}

Authors declare no conflict of interest.

\section{References}

[1] Lundh, M., Scully, S.S., Mandrup-Poulsen, T. and Wagner, B.K. (2013) Small-Molecule Inhibition of Inflammatory Beta-Cell Death. Diabetes, Obesity \& Metabolism, 15, 176-184. http://dx.doi.org/10.1111/dom.12158

[2] Donath, M.Y., Schumann, D.M., Faulenbach, M., Ellingsgaard, H., Perren, A. and Ehses, J.A. (2008) Islet Inflammation in Type 2 Diabetes: From Metabolic Stress to Therapy. Diabetes Care, 31, S161-S164. http://dx.doi.org/10.2337/dc08-s243

[3] Abdulreda, M.H. and Berggren, P.O. (2013) Islet Inflammation in Plain Sight. Diabetes, Obesity \& Metabolism, 15, 105-116. http://dx.doi.org/10.1111/dom.12160

[4] Jain, D., Weber, G., Eberhard, D., Mehana, A.E., Eglinger, J., Welters, A., Bartosinska, B., Jeruschke, K., Weiss, J., Päth, G., Ariga, H., Seufert, J. and Lammert, E. (2015) DJ-1 Protects Pancreatic Beta Cells from Cytokine- and Streptozotocin-Mediated Cell Death. PLoS One, 10, e0138535. http://dx.doi.org/10.1371/journal.pone.0138535

[5] Molena-Fernandes, C., Bersani-Amado, C.A., Ferraro, Z.M., Hintze, L.J., Nardo Jr., N. and Cuman, R.K. (2015) Effects of Exercise and Metformin on the Prevention of Glucose Intolerance: A Comparative Study. Brazilian Journal of Medical and Biological Research, 48, 1101-1108. (Epub Ahead of Print)

[6] Dongway, A.C., Faggad, A.S., Zaki, H.Y. and Abdalla, B.E. (2015) C-Reactive Protein Is Associated with Low-Density Lipoprotein Cholesterol and Obesity in Type 2 Diabetic Sudanese. Diabetes, Obesity \& Metabolism: Targets and Therapy, 8, 427-435.

[7] Luijks, H., Biermans, M., Bor, H., van Weel, C., Lagro-Janssen, T., de Grauw, W. and Schermer, T. (2015) The Effect of Comorbidity on Glycemic Control and Systolic Blood Pressure in Type 2 Diabetes: A Cohort Study with 5 Year Follow-Up in Primary Care. PLoS One, 10, e0138662. http://dx.doi.org/10.1371/journal.pone.0138662

[8] Zethelius, B. and Cederholm, J. (2015) Comparison between Indexes of Insulin Resistance for Risk Prediction of Cardiovascular Diseases or Development of Diabetes. Diabetes Research and Clinical Practice, 110, 183-192.

[9] Liang, K.W., Lee, W., Lee, W.L., Liao, Y.C., Wang, K.Y., Lee, I.T., Wang, J.S. and Sheu, W.H. (2015) Circulating Adipokines and Insulin Resistance in Subjects with Combined Cardiac and Metabolic Syndrome X. Diabetology \& Metabolic Syndrome, 7, 83. http://dx.doi.org/10.1186/s13098-015-0078-4

[10] Alie, N., Eldib, M., Fayad, Z.A. and Mani, V. (2015) Inflammation, Atherosclerosis, and Coronary Artery Disease: PET/CT for the Evaluation of Atherosclerosis and Inflammation. Clinical Medicine Insights: Cardiology, 8, 13-21.

[11] Schmidt, F.M., Weschenfelder, J. and Sander, C. (2015) Inflammatory Cytokines in General and Central Obesity and Modulating Effects of Physical Activity. PLoS ONE, 10, e0121971. http://dx.doi.org/10.1371/journal.pone.0121971

[12] Contreras-Rodríguez, A., Gómez-Díaz, R.A., Tanus-Hajj, J., Talavera, J.O., Mondragón-González, R. and Wacher, N.H. (2015) Carotid Intima-Media Thickness, Ankle-Arm Index, and Inflammation Profile in Mexican Patients with Early and Late Onset Type 2 Diabetes. Revista de Investigación Clínica, 67, 240-249.

[13] Kawada, T., Otsuka, T., Inagaki, H., Wakayama, Y. and Katsumata, M. (2015) Biological Markers, Lifestyles and Metabolic Syndrome in Workers. Diabetes \& Metabolic Syndrome: Clinical Research \& Reviews, 9, 71-73.

http://dx.doi.org/10.1016/j.dsx.2015.02.009 
[14] Coffman, E. and Richmond-Bryant, J. (2015) Multiple Biomarker Models for Improved Risk Estimation of Specific Cardiovascular Diseases Related to Metabolic Syndrome: A Cross-Sectional Study. Population Health Metrics, 13, 7. http://dx.doi.org/10.1186/s12963-015-0041-5

[15] Lloyd-Jones, D.M., Hong, Y. and Labarthe, D. (2010) American Heart Association Strategic Planning Task Force and Statistics Committee. Defining and Setting National Goals for Cardiovascular Health Promotion and Disease Reduction: The American Heart Association’s Strategic Impact Goal through 2020 and beyond. Circulation, 121, 586-613. http://dx.doi.org/10.1161/CIRCULATIONAHA.109.192703

[16] Tanimoto, M., Kanazawa, A., Hirose, T., Yoshihara, T., Kobayashi-Kimura, S., Nakanishi, R., Tosaka, Y., Sasaki-Omote, R., Kudo-Fujimaki, K., Komiya, K., Ikeda, F., Someya, Y., Mita, T., Fujitani, Y. and Watada, H. (2015) Comparison of Sitagliptin with Nateglinide on Postprandial Glucose and Related Hormones in Drug-Naïve Japanese Patients with Type 2 Diabetes Mellitus: A Pilot Study. Journal of Diabetes Investigation, 6, 560-566. http://dx.doi.org/10.1111/jdi.12338

[17] Barrot-de la Puente, J., Mata-Cases, M., Franch-Nadal, J., Mundet-Tudurí, X., Casellas, A., Fernandez-Real, J.M. and Mauricio, D. (2015) Older Type 2 Diabetic Patients Are More Likely to Achieve Glycaemic and Cardiovascular Risk Factors Targets than Younger Patients: Analysis of a Primary Care Database. International Journal of Clinical Practice, 69, 1486-1495. http://dx.doi.org/10.1111/ijcp.12741

[18] Du, H., Dong, C.Y. and Lin, Q.Y. (2015) Risk Factors of Acute Myocardial Infarction in Middle-Aged and Adolescent People (< 45 Years) in Yantai. BMC Cardiovascular Disorders, 15, 106. http://dx.doi.org/10.1186/s12872-015-0102-5

[19] Roca-Rodríguez, M.D., Tapia-Guerrero, M.J., Maraver-Selfa, S., Tinahones, F.J. and Mancha-Doblas, I. (2015) Lixisenatide Clinical Experience on Patients with Type 2 Diabetes Andobesity in Endocrinology Offices in Malaga. Endocrinología y Nutrición, 62, 512-514. http://dx.doi.org/10.1016/j.endonu.2015.07.004

[20] Galhardo, J. and Shield, J. (2015) The Role of Haemoglobin A1c in Screening Obese Children and Adolescents for Glucose Intolerance and Type 2 Diabetes. Acta Médica Portuguesa, 28, 307-315.

[21] Lopategi, A., López-Vicario, C., Alcaraz-Quiles, J., García-Alonso, V., Rius, B., Titos, E. and Clària, J. (2015) Role of Bioactive Lipid Mediators in Obese Adipose Tissue Inflammation and Endocrine Dysfunction. Molecular and Cellular Endocrinology, 419, 44-59. http://dx.doi.org/10.1016/j.mce.2015.09.033

[22] Sun, M., Zhang, L., Chen, A., Liu, X., Shao, X. and Zou, H. (2015) Association of C-Reactive Protein and Metabolic Disorder in a Chinese Population. International Journal of Environmental Research and Public Health, 12, 8228-8242. http://dx.doi.org/10.3390/ijerph120708228

[23] Nowotny, K., Jung, T., Höhn, A., Weber, D. and Grune, T. (2015) Advanced Glycation End Products and Oxidative Stress in Type 2 Diabetes Mellitus. Biomolecules, 5, 194-222. http://dx.doi.org/10.3390/biom5010194

[24] Schuster, D.P. (2010) Obesity and the Development of Type 2 Diabetes: The Effects of Fatty Tissue Inflammation. Diabetes, Metabolic Syndrome and Obesity: Targets and Therapy, 3, 253-262. http://dx.doi.org/10.2147/dmsott.s7354

[25] Vargas, R., Ryder, E., Diez-Ewald, M., Mosquera, J., Durán, A., Valero, N., Pedreañez, A., Peña, C. and Fernández, E. (2015) Increased C-Reactive Protein and Decreased Interleukin-2 Content in Serum from Obese Individuals with or without Insulin Resistance: Associations with Leukocyte Count and Insulin and Adiponectin Content. Diabetes \& Metabolic Syndrome: Clinical Research \& Reviews. [Epub ahead of print] http://dx.doi.org/10.1016/j.dsx.2015.09.007

[26] Slagter, S.N., van Vliet-Ostaptchouk, J.V., van Beek, A.P., Keers, J.C., Lutgers, H.L., van der Klauw, M.M. and Wolffenbuttel, B.H. (2015) Health-Related Quality of Life in Relation to Obesity Grade, Type 2 Diabetes, Metabolic Syndrome and Inflammation. PLoS ONE, 10, e0140599. http://dx.doi.org/10.1371/journal.pone.0140599

[27] Liu, Y., Luo, B., Shi, R., Wang, J., Liu, Z., Liu, W., Wang, S. and Zhang, Z. (2015) Nonerythropoietic Erythropoietin-Derived Peptide Suppresses Adipogenesis, Inflammation, Obesity and Insulin Resistance. Scientific Reports, 5, 15134. http://dx.doi.org/10.1038/srep15134

[28] Li, S., Zhang, Y., Guo, Y.L., Zhu, C.G., Wu, N.Q., Qing, P., Gao, Y., Sun, J., Liu, G., Dong, Q. and Li, J.J. (2015) Effect of Glycemic and Lipid Achievements on Clinical Outcomes Type 2 Diabetic, Chinese Patients with Stable Coronary Artery Disease. Journal of Diabetes and Its Complications, 30, 115-120. http://dx.doi.org/10.1016/j.jdiacomp.2015.09.016

[29] Zeb, I. and Budoff, M. (2015) Coronary Artery Calcium Screening: Does It Perform Better than Other Cardiovascular Risk Stratification Tools? International Journal of Molecular Sciences, 16, 6606-6620. http://dx.doi.org/10.3390/ijms16036606

[30] Maruyama, C., Imamura, K. and Teramoto, T. (2003) Assessment of LDL Particle Size by Triglyceride/HDL-Cholesterol Ratio in Non-Diabetic, Healthy Subjects without Prominent Hyperlipidemia. Journal of Atherosclerosis and Thrombosis, 10, 186-191. http://dx.doi.org/10.5551/jat.10.186

[31] Vargas, H.O., Nunes, S.O. and Barbosa, D.S. (2014) Castelli Risk Indexes 1 and 2 Are Higher in Major Depression but Other Characteristics of the Metabolic Syndrome Are Not Specific to Mood Disorders. Life Sciences, 102, 65-71.

http://dx.doi.org/10.1016/j.lfs.2014.02.033 
[32] Vieira, E.A., Carvalho, W.A., Aras, R.J., Couto, F.D. and Couto, R.D. (2011) Triglyceride/HDL-C Ratio as a Cardiovascular Risk Indicator in Chronic Alcoholic Patients. Jornal Brasileiro de Patologia e Medicina Laboratorial, 47, 113-118. http://dx.doi.org/10.1590/S1676-24442011000200004

[33] Yadav, R., Liu, Y. and Kwok, S. (2015) Effect of Extended-Release Niacin on High Density Lipoprotein (HDL) Functionality, Lipoprotein Metabolism, and Mediators of Vascular Inflammation in Statin-Treated Patients. Journal of the American Heart Association, 4, e001508. http://dx.doi.org/10.1161/JAHA.114.001508

[34] Mogarekar, M.R. and Kulkarni, S.K. (2015) Quality or Quantity? A Study of Small Dense Low-Density Lipoprotein Cholesterol, Paraoxonase 1 and Lipid Profile in Postmenopausal Women. Archives of Medical Research, 46, 534-538.

[35] Manabe, Y., Morihara, R. and Matsuzono, K. (2015) Estimation of the Presence of Small Dense Lipoprotein Cholesterol in Acute Ischemic Stroke. Neurology International, 7, 5973. http://dx.doi.org/10.4081/ni.2015.5973

[36] Valabhji, J. and Elkeles, R.S. (2003) Dyslipidemia in Type 2 Diabetes: Epidemiology and Biochemistry. British Journal of Diabetes \& Vascular Disease, 3, 184-189. http://dx.doi.org/10.1177/14746514030030030501

[37] American Diabetes Association (2011) Diagnosis and Classification of Diabetes Mellitus. Diabetes Care, 34, S62-S69. http://dx.doi.org/10.2337/dc11-s062

[38] Chen, S.-C. and Tseng, C.-H. (2013) Dyslipidemia, Kidney Disease, and Cardiovascular Disease in Diabetic Patients. The Review of Diabetic Studies, 10, 88-100. http://dx.doi.org/10.1900/RDS.2013.10.88

[39] Meshkani, R. and Adeli, K. (2009) Hepatic Insulin Resistance, Metabolic Syndrome and Cardiovascular Disease. Clinical Biochemistry, 42, 1331-1346. http://dx.doi.org/10.1016/j.clinbiochem.2009.05.018 